\title{
PENDAMPINGAN DALAM OPERASIONALISASI SISTEM INFORMASI MANAJEMEN (SIM) KELOMPOK NELAYAN DESA MADONG
}

\author{
Assembly In Operationalization Management Information System (MIS) Madong Village \\ Fisheries Group
}

\author{
Roni Kurniawan ${ }^{1 *}$, Lia Suprihartini ${ }^{1}$ \\ Jurusan Manajemen, Fakultas Ekonomi, Universitas Maritim Raja Ali Haji, Tanjungpinang \\ *Korespondensi : ronik@umrah.ac.id
}

\begin{abstract}
ABSTRAK
Jenis kegiatan pengabdian ini adalah penyuluhan yang dilakukan dengan metode ceramah, tanya jawab serta pelatihan penggunaan aplikasi langsung yang sudah dibuat kepada sasaran program agar sasaran program dapat mengaplikasikan program SIM yang telah dirancang untuk kepentingan pemprosesan data base secara efektif dan efisien dengan Ms. Acces sampai pada akhir bulan Oktober 2018. Adapun tujuan kegiatan pengabdian masyarakat yang dilakukan yaitu (1) untuk membantu kelompok nelayan Desa Madong dalam memahami pentingnya database pada sistem informasi manajemen (2) untuk membantu cara membuat laporan pada Koperasi Kelompok nelayan Desa Madong (3) untuk melakukan pendampingan bagaimana cara mengelola database pada koperasi kelompok nelayan.
\end{abstract}

Kata kunci : Database, Kelompok Nelayan Madong, Sistem Informasi Manajemen

\begin{abstract}
This type of service activity is counseling conducted by lecture method, question and answer and training on the use of direct applications that have been made to the program target so that the program targets can apply MIS programs that have been designed for the benefit of processing data bases effectively and efficiently with Ms. Access until the end of October 2018. The objectives of community service activities are (1) to assist Madong Village fishermen groups in understanding the importance of databases in management information systems (2) to assist in how to report to the Madong Village Fisheries Cooperative Group (3) to provide assistance on how to manage databases at fishing group cooperatives.
\end{abstract}

Keywords: Database, Madong Fishermen Group, Management Information System

\section{PENDAHULUAN}

Penggunaan sistem informasi sangat dibutuhkan dalam meningkatkan produktivitas dalam suatu perusahaan dengan semakin banyaknya persaingan, membuat perusaahaan berpikir keras dalam menjalankan proses bisnisnya. Untuk itu digunakanlah suatu sistem database dalam pengelolaan data. Penggunaan database dalam perusahaan merupakan salah satu hal yang sangat wajib untuk mendukung kegiatan-kegiatan yang ada di dalam suatu organisasi atau perusahaan.

Sistem informasi manajemen menurut Jogiyanto Hartono (2000:700) adalah kumpulan dari interaksi sistem-sistem informasi yang bertanggung jawab 
mengumpulkan dan mengolah data untuk menyediakan informasi yang berguna untuk semua tingkat manajemen di dalam kegiatan perencanaan dan pengendalian

Pada kondisi yang ada sekarang ini, Kelompok nelayan Desa Madong masih menggunakan catatan manual untuk memproses transaksi pada koperasinya tentunya hal tersebut tidaklah bisa diproses dengan sempurna atas transaksi yang berjalan sehingga mendapatkan kesulitan dalam hal penetapan keputusan secara cepat. Sebagai contoh bahwa memerlukan waktu yang relative lama untuk mengetahui jumlah penyetoran anggota koperasi, sudah berapa kali anggota meminjam, berapa total uang masuk setiap anggotanya dan siapa yang belum bayar. Oleh karena kondisi tersebut sangat penting bagi Kelompok nelayan Desa Madong untuk mempunyai sistem informasi yang cukup handal untuk mempermudah dalam proses.

Dalam kegiatan pengabdian masyarakat yang akan dilakukan adalah pendampingan di Kelompok nelayan Desa Madong. Suharto (2009:93) menguraikan bahwa pendampingan merupakan satu strategi yang sangat menentukan keberhasilan program pemberdayaan masyarakat. Pendampingan sebagai suatu strategi yang umum digunakan oleh pemerintah dan lembaga non profit dalam upaya meningkatkan mutu dan kualitas dari sumber daya manusia, sehingga mampu mengindentifikasikan dirinya sebagai bagian dari permasalahan yang dialami dan berupaya untuk mencari alternative pemecahan masalah yang dihadapi. Kemampuan sumber daya manusia sangat dipengaruhi oleh keberdayaan dirinya sendiri. Oleh karena itu sangat dibutuhkan kegiatan pemberdayaan disetiap kegiatan pendampingan

Berdasarkan uraian tersebut, menarik kiranya untuk melakukan pendampingan bagi Koperasi Nelayan Desa Madong agar dapat membantu meningkatkan kehandalan pemrosesan data setiap transaksi yang dilakukan. Selain itu, diharapkan dapat menambah pengetahuan bagi masyarakat nelayan untuk menyadari bahwa kemampuan teknologi komputer dapat mempermudah pekerjaan.

\section{METODE}

\section{Waktu dan Tempat}

Kegiatan dilaksanakan selama 6 bulan, mulai Mei 2018 - Oktober 2018 di Desa Madong, Kelurahan Kampung Bugis, Kota Tanjungpinang, Provinsi Kepulauan Riau

\section{Metode Pelaksanaan dan Analisis Data}

Metode palaksanaan kegiatan secara umum terdiri atas penyuluhan dan pendampingan. Sebelum dilakukan kegiatan penyuluhan ataupun pendampingan, terlebih dulu dilakukan pemetaan permasalahan dan kebutuhan melalui metode survei, dan diskusi dengan ketua dan anggota kelompok nelayan

\section{HASIL DAN PEMBAHASAN}

Pengabdian masyarakat di Kelompok Nelayan Desa Madong ini telah dilaksanakan sejak bulan Mei - Oktober 2018 . Adapun materi yang disampaikan dalam pendampingan pengabdian ini adalah sebagai berikut :

1. Pentingnya sistem informasi manajemen bagi organisasi : Lia Suprihartini, SE., MM

2. Penjelasan SOP system informasi manajemen: Lia Suprihartini, SE., MM

3. Pemberian Aplikasi kepada kelompok nelayan (Koperasi) berupa softcopy : Roni Kurniawan, M.Si

4. Praktek menggunkan system yang telah dibuat dengan memperlihatkan hasil output laporan : Roni Kurniawan, M.Si 


\section{Pelaksanaan}

Tabel 1 Tahapan Pengabdian Kepada masyarakat

\begin{tabular}{|c|c|c|c|c|}
\hline No & Tahapan & Indikator & Ketercapaian & Keterangan \\
\hline 1 & $\begin{array}{l}\text { Sosialisasi akan } \\
\text { diadakannya } \\
\text { kegiatan } \\
\text { pengabdian } \\
\text { masyarakat pada } \\
\text { kelompok } \\
\text { nelayan Desa } \\
\text { Madong }\end{array}$ & $\begin{array}{l}\text { 1. Kordinasi dengan Ketua } \\
\text { Kelompok Nelayan } \\
\text { 2. Peninjauan lokasi } \\
\text { koperasi } \\
\text { pengabdian mitra } \\
\text { 3. Peninjauan tempat } \\
\text { untuk kegiatan } \\
\text { penyuluhan kepada } \\
\text { mitra pengabdian yang } \\
\text { berlokasi di rumah } \\
\text { ketua kelompok } \\
\text { nelayan Desa Madong } \\
\text { dan di tempat koperasi }\end{array}$ & $100 \%$ & $\begin{array}{l}\text { Tercapai } \\
\text { Tercapai } \\
\text { Tercapai }\end{array}$ \\
\hline 2 & $\begin{array}{l}\text { Identifikasi } \\
\text { alat-alat yang } \\
\text { dibutuhkan oleh } \\
\text { mitra } \\
\text { pengabdian }\end{array}$ & $\begin{array}{l}\text { 1. Pengembangan Ide } \\
\text { 2. Pembuatan Design }\end{array}$ & $\begin{array}{l}100 \% \\
100 \%\end{array}$ & $\begin{array}{l}\text { Tercapai } \\
\text { Tercapai }\end{array}$ \\
\hline 3 & $\begin{array}{l}\text { Mempersiapkan } \\
\text { kegiatan } \\
\text { pendampingan } \\
\text { kepada mitra } \\
\text { pengabdian } \\
\text { tentang aplikasi } \\
\text { koperasi }\end{array}$ & $\begin{array}{l}\text { Proses Pembuatan dan } \\
\text { perancangan Aplikasi } \\
\text { Koperasi berbasis Desktop }\end{array}$ & $100 \%$ & Tercapai \\
\hline 4 & $\begin{array}{l}\text { Pengaplikasian } \\
\text { kegiatan } \\
\text { pengabdian pada } \\
\text { kelompok nelayan }\end{array}$ & $\begin{array}{l}\text { 1. Bertempat di Koperasi } \\
\text { Nelayan } \\
\text { 2. Anggota nelayan } \\
\text { mengikuti jalannya } \\
\text { kegiatan }\end{array}$ & $100 \%$ & Tercapai \\
\hline 5 & $\begin{array}{l}\text { Kegiatan } \\
\text { Keberlanjutan }\end{array}$ & $\begin{array}{l}\text { 1. Monitoring Aplikasi } \\
\text { 2. Monitoring Operator }\end{array}$ & $\begin{array}{l}100 \% \\
100 \%\end{array}$ & $\begin{array}{l}\text { Tercapai } \\
\text { Tercapai }\end{array}$ \\
\hline 6 & Laporan & & $100 \%$ & \\
\hline
\end{tabular}




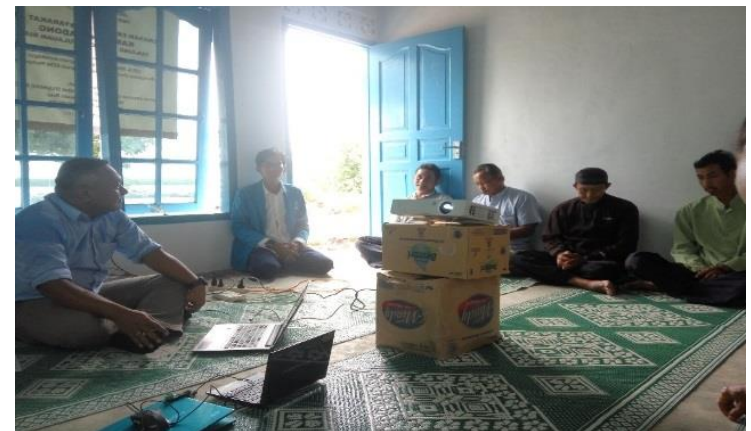

Gambar 1 Pemberian Ceramah, Diskusi dan Pelatihan

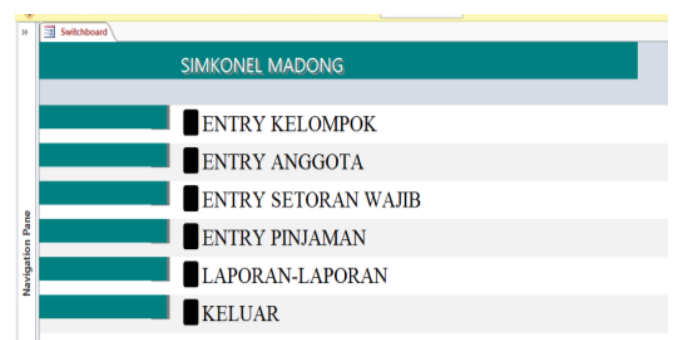

Gambar 2 Bentuk Menu Aplikasi SIMKONEL (Sistem Informasi Manajemen Koperasi Nelayan)

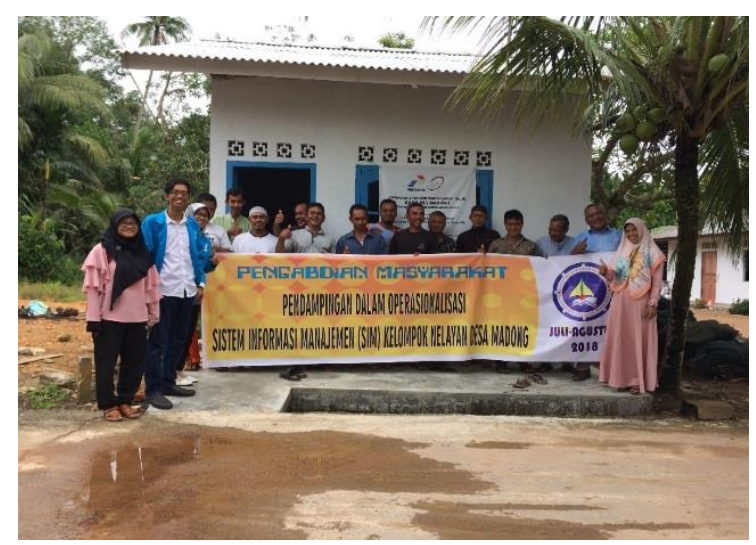

Gambar 3 Selesai Acara Pengabdian

\section{Monitoring dan Evaluasi}

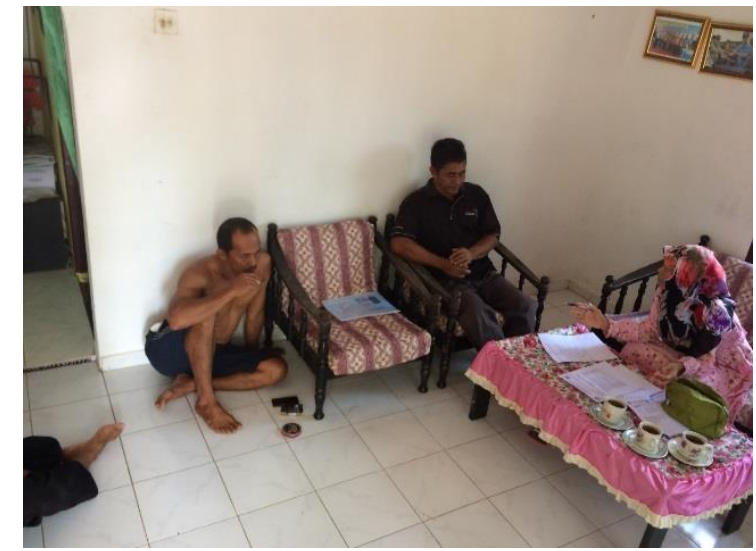

Gambar 4 Monitoring Dengan Ketua dan Anggota Koperasi

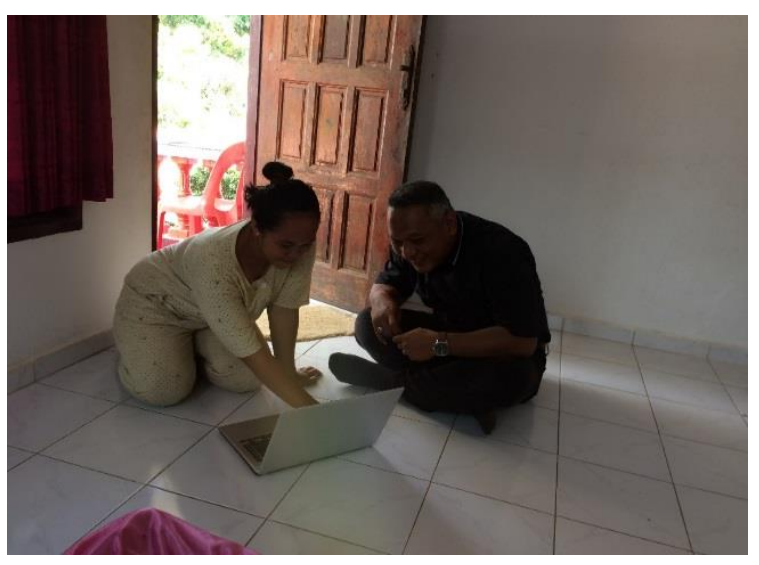

Gambar 5 Monitoring Dengan Operator

\section{KESIMPULAN}

Pengabdian masyarakat telah dapat dijalankan dengan baik dan tanpa halangan yang berarti. Dengan kerjasama tim pengabdian yang baik dan peran serta aktif dari setiap anggota koperasi dalam kegiatan pengabdian ini maka semuanya telah berjalan sesuai yang diharapkan dan harapannya dapat memberikan manfaat bagi mitra pengabdian masyarakat dalam keberlanjutan usaha koperasi yang dijalankan, tentunya koperasi bisa berjalan dengan baik bukan hanya merekam iuran anggota saja tetapi menjadi koperasi yang bisa memberi peminjaman modal usaha bagi para anggotanya karena sistem dalam 
aplikasi yang sudah dikembangkan sanggup melakukan setiap transaksi dengan demikian koperasi nelayan Desa Madong dapat menjadi contoh yang baik kepada koperasi sejenis dalam hal pemakaian teknologi tepat guna dengan sistem informasi manajemen yang handal.

\section{DAFTAR PUSTAKA}

Hartono, J. 2000. Pengenalan Komputer : Dasar Ilmu Komputer, Pemograman, Sistem Informasi, dan Intelegensi
Buatan.. Edisi 3. Cet. Kedua. Andi. Yogyakarta

Kurniawan R, 2017. Sistem Informasi Manajemen (Membuat Aplikasi Gaji Pegawai). Tanjungpinang : UMRAH Press.

Suharto, Edi. 2009. Membangun Masyarakat Membardayakan Rakyat, PT Refika Aditama. Bandung

Diterima : 8 Oktober 2018

Disetujui : 29 November 2018 